\title{
¿Al fin una Corte Constitucional?: Breve revisión del desarrollo de los derechos y el control constitucional en la jurisprudencia reciente (2019-2020).
}

\author{
At last, a Constitutional Court?: A brief review of \\ fundamental rights' development and constitutional \\ review in recent jurisprudence (2019-2020)
}

Msc. Pablo Valdivieso-Kastner*

Pontificia Universidad Católica del Ecuador

LLM. José Luis Castro-Montero**

Universidad Andina Simón Bolívar, sede Ecuador

Infomación del Artículo

Original - Ruptura, 2020

Artículo recibido / Received: 10 de septiembre, 2020

Artículo aceptado / Accepted: 03 de diciembre, 2020

\section{Citación}

Valdivieso, P. y Castro, J. (2020). ¿Al fin una Corte Constitucional?: Breve revisión del desarrollo de los derechos y el control constitucional en la jurisprudencia reciente (2019-2020). Revista Ruptura de la Asociación Escuela de Derecho PUCE. Edición 2020, p (89-131).

DOI: $10.26807 /$ rr.vi02.55

* Abogado por la PUCE. Magíster en Ciencia Política por London School of Economics and Political Science. Es docente de Derecho Constitucional en la PUCE y asesor en la Corte Constitucional. Correo electrónico: pablo.valdivieso.kastner@gmail.com

** Abogado por la PUCE. Especialista Superior en Derecho Constitucional por la UASB, sede Ecuador. Magíster en investigación de Derecho por Tilburg University y KU Leuven. Es docente de Derecho Constitucional en la UASB y asesor en la Corte Constitucional. Correo electrónico: j.1.castromontero1@gmail.com 
Resumen: Este trabajo contiene una revisión de las principales sentencias emitidas por la Corte Constitucional del Ecuador en su primer año de funciones. El organismo se caracteriza por ser un Tribunal de cierre con prerrogativas de control de constitucionalidad fuerte. Dentro de este contexto, las decisiones tomadas han desarrollado el contenido de derechos fundamentales al tiempo que han revertido varios precedentes jurisprudenciales. La primera parte presenta aquellas sentencias que avanzan los derechos a la igualdad, a la libertad de expresión y a la libertad ambulatoria, los derechos de participación, de las comunidades y pueblos indígenas, a la salud y a la seguridad social. La segunda parte incluye sentencias que se encargan del control de constitucionalidad de propuestas de reforma constitucional, consultas populares, leyes y tratados internacionales. Finalmente, apuntamos algunos retos que mantiene esta Corte de cara a lograr uniformidad en la interpretación y afianzar su independencia e institucionalidad.

Palabras clave: Corte Constitucional, derechos fundamentales, garantías jurisdiccionales, jurisprudencia Ecuador, control de constitucionalidad.

\begin{abstract}
This work encompasses the most salient judicial decisions issued by the Ecuadorian Constitutional Court along its first year in office. The ECC exercises strong constitutional review, i.e., its interpretation of the constitution is binding and it cannot be overturned by other powers. In this context, the ECC has not only advanced constitutional rights, but also reversed some of its previous rulings. In the first section we survey rulings that advanced equality, freedom of expression, freedom of movement, political rights, collective rights and the right to health and to social security. The second section comprises decisions concerning judicial review of constitutional amendments, referendum, legislation and international treaties. Finally, we conclude by pointing out ECC's challenges towards achieving hermeneutical consistency and a certain degree of independence and institutionalization.
\end{abstract}

Keywords: Constitutional Court, fundamental rights, judicial guarantees, jurisprudence in Ecuador, constitutional review. 


\section{Introducción}

La Constitución ecuatoriana de 2008 otorga un protagonismo sin precedentes a la Corte Constitucional (en adelante CC o "la Corte"). Dentro del engranaje institucional que consagra nuestra Constitución, la CC adquiere un papel central en el ejercicio del control, interpretación y administración de justicia constitucional, caracterizado por sus amplias atribuciones en materia de control de la supremacía de la Carta Fundamental y protección de los derechos constitucionales. En la teoría, este sistema de control constitucional fuerte imaginaba a la Corte como un actor capaz de hacer efectivo el goce de los derechos y las garantías, de impulsar cambios sociales, de preservar el sistema de frenos y contrapesos, cimentando su legitimidad sobre la base de una naciente cultura constitucional y democrática. En la práctica, muy a pesar de sus amplias competencias, la CC ha tenido continuas dificultades para consolidarse como una institución que garantice la supremacía de la Constitución y el pleno ejercicio de los derechos. Desde su creación en 2008, el organismo estuve fuertemente influenciado por los influjos de orden político provenientes de las otras funciones del Estado, especialmente de la Función Ejecutiva (Castro-Montero y van Dijck, 2017; Jaramillo Jassir, 2013).

Desde 2008 a 2012, los entonces miembros del ex Tribunal Constitucional (organismo que antecedió a la actual Corte) se autoproclamaron como jueces de la CC "para el periodo de transición” (Oyarte, 2015). En 2012, en medio de constantes críticas por la falta de independencia del organismo, se realizó un cuestionado concurso público para designar a jueces constitucionales permanentes (Salgado, 2013). En 2015, se dio la primera renovación de tres de los nueve jueces de la Corte. A pesar de la renovación parcial de magistrados, el escaso desarrollo jurisprudencial de los derechos constitucionales y la falta de independencia, en especial al momento de tratar aquellos casos en los que el Ejecutivo y el partido de gobierno tenían algún tipo de interés, siguieron obstaculizando una auténtica institucionalización del organismo (González-Jácome, 2017; Landau, 2013).

En el año 2018 el gobierno llamó a una consulta popular. Uno de los objetivos de la consulta fue la creación de un organismo transitorio 
- Consejo de Participación Ciudadana y Control Social Transitorio (CPCCS-T)- cuyo mandato consistió en evaluar el funcionamiento de varias entidades de control (Trujillo, 2019). El CPCCS-T evaluó a la Corte Constitucional y resolvió cesar en funciones a los jueces de este organismo debido a la falta de independencia y al retraso en el despacho de procesos. De esta forma, la Corte entró en un periodo de vacancia durante seis meses. A la par, el CPCCS-T organizó un concurso de oposición y méritos para nombrar nuevos jueces. Los ganadores del concurso se posesionaron y comenzaron sus funciones en febrero de 2019.

Este trabajo presenta una crónica jurisprudencial de las que, en nuestro criterio, son las sentencias más importantes en términos de desarrollo de derechos fundamentales, emitidas durante el primer año de labores de la Corte Constitucional (febrero 2019 - febrero 2020). Esta crónica no tiene como objetivo analizar críticamente la jurisprudencia, sino que más bien revisa de manera panorámica los principales pronunciamientos del máximo órgano de interpretación constitucional en el Ecuador. La importancia de este documento radica en que recoge la novedad de algunas sentencias respecto del desarrollo del contenido de derechos, la reversión de fallos previos y la activación de atribuciones que la CC no había ejercido previamente, en especial del mecanismo de selección y revisión.

Este trabajo se organiza de la siguiente manera: la primera sección comprende una descripción de las principales atribuciones de la CC. La segunda sección revisa las principales sentencias en función de grupos de derechos. Así, se enfocan derechos de igualdad y libertad, derechos de participación, derechos del buen vivir y derechos colectivos. Además, se hace especial mención sobre el desarrollo de la garantía de habeas corpus en conexión con otros derechos. La tercera parte abarca algunas sentencias de control de constitucionalidad como reforma constitucional, inconstitucionalidad de norma y Constitución económica. En la parte final apuntamos las conclusiones que se derivan del contenido previo. 


\section{La Corte Constitucional y sus competencias}

La CC está compuesta por nueve jueces, que tienen un período fijo de nueve años en el cargo -sin posibilidad de reelección inmediata- y son renovados por tercios cada tres años ${ }^{1}$. Los jueces de este Tribunal no están sujetos a juicio político y tampoco pueden ser removidos por el ente que los designa, aunque están sujetos a otros controles de la función pública.

La CC es el máximo órgano de control, interpretación y administración de justicia constitucional, por lo que es considerado un tribunal de cierre con un control fuerte. Esto implica la existencia de una Constitución rígida que otorga amplias atribuciones al órgano de control, cuyas decisiones no pueden ser revertidas por otros órganos, particularmente por el Legislativo (Grijalva, 2012a).

Dentro de sus facultades de control ex ante, la CC dictamina la constitucionalidad de tratados internacionales, convocatorias a consultas populares nacionales o locales, objeciones presidenciales a proyectos de ley, propuestas de reforma constitucional y proyectos de estatutos autonómicos (Oyarte, 2015). También se encarga del control jurídico de actos políticos al emitir dictamen de admisibilidad sobre el inicio juicio político contra el Presidente y dictamen de favorabilidad sobre la destitución del Presidente o disolución de la Asamblea Nacional, cuando se alegue la arrogación de funciones.

Con respecto al control abstracto ex post de constitucionalidad, la CC interviene como un actor encargado de garantizar la supremacía

1 Para la selección y nombramiento de los jueces se conforma una comisión calificadora que lleva a cabo un concurso público en el que participan 9 candidatos propuestos por cada una de las siguientes funciones: Ejecutivo, Legislativo y Transparencia y Control Social. El concurso comprende fases de comparecencia oral, impugnación y culmina con la designación y posterior posesión ante la Asamblea Nacional. Los 9 jueces eligen a un presidente y aun vicepresidente que duran en el cargo un lapso de 3 años. De otro lado, las decisiones dentro de la CC se toman por una mayoría absoluta y tienen el carácter de definitivas e inapelables. 
de la Carta Fundamental frente a normas de inferior jerarquía. En este orden, sus atribuciones le permiten decidir la expulsión del ordenamiento jurídico de normas ${ }^{2}$ o actos administrativos -por el fondo o la forma-, a través de una acción pública de inconstitucionalidad o una acción de inconstitucionalidad de actos administrativos con efectos generales, respectivamente (Guerrero, 2011). Así mismo, mediante una acción de inconstitucionalidad por omisión, la CC dictamina sobre mandatos constitucionales de desarrollo normativo que no han sido atendidos por instituciones del Estado o sobre normativa que tiene graves deficiencias de constitucionalidad, cuando se trata de una omisión relativa (Oyarte, 2015; Valle, 2010).

En cuanto al control concreto ex post, si un juez ordinario tiene dudas razonables sobre la constitucionalidad de una norma que debe aplicar para resolver un caso concreto, debe suspender la sustanciación del caso y elevarlo a un pronunciamiento de la CC a través de una consulta de constitucionalidad de norma (Romero, 2017).

Por otra parte, existen garantías jurisdiccionales constitucionales que la CC conoce de forma directa y otras que se tramitan ante los jueces inferiores. El primer grupo de garantías jurisdiccionales incluye mecanismos que buscan la tutela de derechos constitucionales que fueron vulnerados por acción u omisión judiciales durante la tramitación de un proceso judicial. Estas garantías son la acción extraordinaria de protección (en adelante "AEP") y la AEP contra decisiones de justicia indígena. En la práctica, alrededor del $80 \%$ de causas que resuelve la CC están relacionadas con la AEP (Oyarte, 2017). Así también, existen garantías jurisdiccionales constitucionales que buscan asegurar el cumplimiento de normas infra constitucionales, informes y sentencias de organismos internacionales -acción por incumplimiento-, y de fallos de la propia CC -acción de incumplimiento-.

2 Según el artículo 436.3 de la Constitución, la facultad de la CC alcanza inclusive a la declaración de inconstitucionalidad de normas conexas a las que se analizan como principales. 
El segundo grupo de garantías abarca acciones que una vez que han sido resueltas por la justicia ordinaria, acceden a la justicia constitucional a través de los procesos de selección y revisión. Aquí se destaca la acción de protección, conocida en la legislación comparada como acción de amparo o tutela (Andrade, 2013; Castro-Montero et al., 2016). Existen otras garantías como el hábeas corpus, el hábeas data, la acción de acceso a la información pública, que buscan proteger derechos como la libertad personal, información personal y el libre acceso a información pública respectivamente, entre otros. Finalmente, dentro de este grupo están las medidas cautelares constitucionales que buscan evitar o hacer cesar una violación inminente de derechos fundamentales (Masapanta, 2013).

El proceso de selección y revisión que realiza la CC consiste precisamente en el escogimiento de los casos de garantías jurisdiccionales más relevantes en función de parámetros como la gravedad, novedad, relevancia e inobservancia de precedentes jurisprudenciales. Una vez que los casos han sido seleccionados, pasan a revisión. Ello permite a la Corte revertir las decisiones adoptadas por los jueces inferiores, desarrollar nuevos parámetros jurisprudenciales sobre derechos constitucionales o consolidar sus precedentes, a través de la emisión de decisiones que constituyen jurisprudencia vinculante (Suárez, 2015). Finalmente, la CC realiza un control jurídico de las declaratorias de estado de excepción, particularmente cuando dentro de ellas se suspenden derechos fundamentales. Además, se encarga de dirimir conflictos de competencias entre las funciones del Estado u otros órganos.

\section{Novedades jurisprudenciales y desarrollo de derechos}

\subsection{Matrimonio igualitario}

En los casos 10-18-CN y 11-18-CN, la CC conoció dos consultas de constitucionalidad de norma en las que interpretó que la Constitución protege el derecho al matrimonio entre parejas del mismo 
sexo. En el caso 10-18-CN, el juez consultante planteó un conflicto entre la Constitución y dos disposiciones de rango legal que, en línea con el artículo 67 de la Constitución, definían al matrimonio como "la unión entre un hombre y una mujer", mientras que en el caso 11-18-CN, la duda de constitucionalidad se fundamentó en la posibilidad de aplicar directamente en el ordenamiento jurídico ecuatoriano la protección convencional del vínculo entre parejas del mismo sexo interpretada por la Corte Interamericana de Derechos Humanos (Corte IDH) en su Opinión Consultiva (OC) No. 24/17 (CC, Sentencia No. 11-18-CN/19, 2019).

En el caso 10-18-CN, la Corte analizó la constitucionalidad de las disposiciones del Código Civil y la Ley Orgánica de Identidad que impedían el matrimonio entre parejas del mismo sexo preguntándose si la Constitución prohibía al legislador instituir el matrimonio entre personas del mismo sexo. A partir de una interpretación axiológica (o principialista), el organismo sostuvo que la esterilidad reproductiva de las parejas homosexuales, la inadecuación de las uniones homosexuales al prototipo de familia tradicional y las visiones que conciben a la homosexualidad como un problema patológico o un desorden moral, entroncadas en una visión católica del matrimonio, no aportan razones constitucionalmente justificadas que obliguen al legislador a prohibir el matrimonio entre personas del mismo sexo.

En el mismo sentido, la CC determinó que la prohibición del matrimonio igualitario desconoce principios constitucionalmente protegidos, como la autonomía de la persona, la laicidad, el buen vivir, la protección constitucional a las diversas formas de familia, la libertad de conciencia, la intimidad y la igualdad formal y material. El modelo de matrimonio en un Estado constitucional, expresó la CC, "no puede ser la proyección de una ética personal (...) sino el reflejo de una ética laica" (CC, Sentencia No. 10-18-CN/19, 2019, p. 15).

La Corte agregó que negar el derecho fundamental al matrimonio en razón de la identidad de las personas impide una interpretación armónica con el bloque de constitucionalidad, en específico con el artículo 17 numeral 2 de la Convención Americana de Derechos Humanos (CADH). En síntesis, la Corte declaró la inconstitucionalidad sustitutiva de los artículos consultados, definiendo al matrimonio 
como la "unión entre dos personas", y exhortó a la Asamblea Nacional a revisar integralmente la legislación para que se brinde un trato igualitario a las parejas del mismo sexo.

En el caso 11-18-CN, la Corte arribó a una conclusión similar a través de un proceso argumentativo distinto. Fundamentalmente, la CC estructuró su decisión a partir de dos líneas argumentativas: la aplicación directa e inmediata de los derechos y garantías consagrados en instrumentos internacionales de derechos humanos y la interpretación sistemática de las disposiciones constitucionales.

En relación con la primera línea argumentativa, cabe notar que la Constitución de 2008 contiene una cláusula de apertura en su artículo 424. Esta disposición permite que los tratados internacionales de derechos humanos que reconocen derechos más favorables a los contenidos en la Constitución prevalezcan sobre cualquier otra norma jurídica o acto del poder público (Bazán, 2014). Ello además se complementa con la obligación de aplicación directa e inmediata de los derechos y garantías reconocidos en los instrumentos internacionales que establecen los artículos 11 numeral 3 y 426 de la Constitución ${ }^{3}$. Sobre la base de estas disposiciones, la Corte señaló que:

los derechos y las garantías reconocidos en la OC 24/17, que interpreta con autoridad la $\mathrm{CADH}$, forman parte de lo que se ha conocido como bloque de constitucionalidad (...) y esto quiere decir que tienen la misma jerarquía normativa constitucional y son directa e inmediatamente aplicables en el sistema jurídico ecuatoriano. (CC, Sentencia No. 11-18CN/19, 2019, párr. 39) ${ }^{4}$

3 El artículo 426 de la Constitución señala: "las juezas y jueces, autoridades administrativas (...) aplicarán directamente las normas constitucionales y las previstas en los instrumentos internacionales de derechos humanos siempre que sean más favorables a las establecidas en la Constitución (...) Los derechos consagrados en la Constitución y los instrumentos internacionales de derechos humanos serán de inmediato cumplimiento y aplicación".

4 La OC No. 24/17 expresa: “(...) es necesario que los Estados garanticen el acceso a todas las figuras ya existentes en los ordenamientos jurídicos internos, incluyendo 
De hecho, la jurisprudencia de la CC ya había reconocido a la OC 24/17 como un instrumento internacional que "por expresa disposición del artículo 424 de la Constitución de la República y por constituir interpretación oficial del órgano interamericano (...) se entiende adherido al texto constitucional" (CC, Sentencia No. 184-18-SEP-CC, 2018, p. 58). Este criterio fue confirmado en el caso 11-18-CN.

En relación con la segunda línea interpretativa, la Corte sostuvo que el derecho al matrimonio debía ser entendido juntamente con la satisfacción de otros derechos constitucionales como el derecho a la familia, al libre desarrollo de la personalidad, a la intimidad personal y familiar, a la identidad, a la libre contratación y, sobre todo, a la igualdad y no discriminación.

Resulta interesante notar el uso plural de métodos interpretativos en la sentencia de mayoría del caso 11-18-CN. Por ejemplo, la Corte utiliza la interpretación "literal, sistemática y favorable", para argumentar que el artículo 67 de la Constitución debe ser interpretado en conjunto con otras disposiciones de la Carta Fundamental y también a la luz de las obligaciones internacionales en materia de derechos humanos, adquiridas por el Estado ecuatoriano. De allí que la Corte concluya que "El Estado debe cumplir de buena fe las obligaciones internacionales (...) y no debe justificar su incumplimiento invocando normas del derecho interno, aún si son constitucionales" (CC, Sentencia No. 11-18-CN/19, 2019, párr. 73).

La Corte también emplea el método evolutivo y afirma que las disposiciones jurídicas deben ser concebidas como instrumentos vivos que ayuden a solucionar los problemas actuales de las personas. De acuerdo con esta perspectiva, la Corte considera al matrimonio como un derecho fundamental para el plan de vida, la dignidad, la igualdad, la identidad y las libertades de las personas del mismo sexo. En efecto, la protección del vínculo matrimonial no puede responder

el derecho al matrimonio, para asegurar la protección de todos los derechos de las familias conformadas por parejas del mismo sexo, sin discriminación con respecto a las que están constituidas por parejas heterosexuales". 
únicamente a las necesidades de aquellos arquetipos tradicionales de la familia, sino que debe cumplir con las exigencias que plantean las sociedades modernas.

Con base en estos razonamientos, la Corte concluye que "la exclusión del derecho al matrimonio por su identidad, es contraria a una sociedad democrática, incluyente, tolerante y sin discriminación" (CC, Sentencia No. 11-18-CN/19, 2019, párr. 115), expresó la Corte, concluyendo que "el artículo 67, que expresa "el matrimonio es la unión entre hombre y mujer", se complementa con la regulación e interpretación de la CADH, realizada por la Corte IDH mediante la OC $24 / 17$, que reconoce el matrimonio entre personas del mismo sexo". (CC, Sentencia No. 11-18-CN/19, 2019, párr. 211).

El voto de minoría, en cambio, sostuvo que la interpretación de la sentencia de mayoría no garantiza la supremacía de la Constitución, produce un efecto de mutación arbitraria de la misma, desconoce la literalidad del artículo 67 del texto constitucional e inobserva los procedimientos de reforma constitucional. Además, expresó que las opiniones consultivas de la Corte IDH no constituyen instrumentos internacionales vinculantes y que, desde el punto de vista constitucional, el mecanismo de consulta de constitucionalidad de norma no habilita a la CC a determinar la aplicación directa de la OC 24-17 en el ordenamiento jurídico ecuatoriano.

\subsection{Unión de hecho entre parejas del mismo sexo}

El caso 603-12-JP llegó a conocimiento de la Corte a través del mecanismo de selección y revisión de garantías jurisdiccionales. En este caso, un tribunal de apelación aceptó una acción de protección propuesta por una pareja homosexual en contra del Registro Civil por la negativa de inscribir su unión de hecho.

La Corte ratificó la decisión del tribunal de apelación y señaló que el artículo 68 de la Constitución protege la unión de hecho entre 
personas del mismo sexo . Además, agregó que la Constitución en su artículo 11 numeral 2 prohíbe la discriminación en razón de la orientación sexual.

Desde la perspectiva argumentativa, la CC empleo un test de igualdad basado en tres parámetros: la comparabilidad entre parejas homosexuales y heterosexuales, la constatación del trato diferenciado en la inscripción de la unión de hecho y la verificación de la desigualdad de resultados. En consecuencia, expresó que la entidad pública demandada tenía "la obligación de registrar la unión de hecho entre dos personas, sin distinción alguna por su orientación sexual. La negativa del registro de la unión de hecho de parejas del mismo sexo es una discriminación y, por tanto, una violación a los derechos reconocidos en la Constitución" (CC, Sentencia No. 603-12-JP/19 (acumulados), 2019, párr. 20).

\subsection{Acciones afirmativas y concursos públicos}

Dentro del caso 7-11-IA, la Corte conoció una acción pública de inconstitucionalidad propuesta en contra de un acto administrativo, en el que el Consejo de la Judicatura convocó a un concurso público de méritos y oposición para la designación de 101 jueces de instancia. Dentro del concurso, se aplicó una medida de acción afirmativa en favor de las mujeres, otorgándoles 2 puntos adicionales en función de lo previsto en el reglamento para el efecto.

El problema jurídico que se planteó la CC fue: "¿la entrega de puntos adicionales a las mujeres en el concurso (...) vulneró el derecho a la igualdad?". Para resolver este problema, la Corte aplicó un "test de igualdad" estructurado en función de cuatro parámetros: i. la legitimidad del objetivo de eliminar toda forma de discriminación por sexo o género; ii. la racionalidad de lograr una igualdad material en la

$5 \quad$ El artículo 68 de la Constitución señala que "la unión estable y monogámica entre dos personas libres de vínculo matrimonial que formen un hogar de hecho, por el lapso y bajo las condiciones y circunstancias que señale la ley, generará los mismos derechos y obligaciones que tienen las familias constituidas mediante matrimonio". 
representación en cargos públicos; iii. la necesidad de la medida para aumentar la representación de mujeres en la rama judicial; y iv. la proporcionalidad en sentido estricto, en la que el organismo destacó que la medida afirmativa protegía derechos de un grupo históricamente excluido y generaba una satisfacción del derecho a la igualdad material alta. En suma, la CC declaró que las acciones afirmativas "no son una excepción al principio de igualdad sino un medio para promover el ejercicio de derechos en igualdad de condiciones" (CC, Sentencia No. 7-11-IA/19, 2019, párr. 21).

\subsection{Estereotipos de género en sentencias}

El caso 525-14-EP fue conocido por la CC a través de una AEP. En este caso, la CC ratificó una decisión en la que la Corte Nacional de Justicia corrigió valoraciones realizadas por jueces inferiores basadas en estereotipos de género. "El uso de estereotipos, preconceptos o prejuicios respecto de las mujeres (...) son el resultado de la situación actual de desigualdad y discriminación que muchas mujeres enfrentan..." (CC, Sentencia No. 525-14-EP/20, 2020, párr. 48), sostuvo la CC, añadiendo que "las mujeres requieren confiar en un sistema judicial libre de prejuicios y estereotipos, y en una judicatura cuya imparcialidad no se vea comprometida por supuestos sesgados" (CC, Sentencia No. 525-14-EP/20, 2020, párr. 49). La Corte además expresó que los operadores de justicia deben adoptar las medidas necesarias para erradicar los estereotipos de género y las prácticas discriminatorias.

\subsection{Libertad de expresión}

En el caso 282-13-JP, la Corte seleccionó una acción de protección presentada por el subsecretario de la Administración Pública en contra del Diario "La Hora". En 2012, este diario publicó un artículo titulado "2012: 71 millones en propaganda”, en el que informó sobre los gastos del gobierno nacional en publicidad. De acuerdo con los personeros de la Administración Pública, el artículo contenía datos erróneos por lo que solicitaron su rectificación, misma que fue publicada bajo el título de "réplica" en el medio de comunicación días más tarde. 
Inconforme con la publicación, el subsecretario de la Administración demandó a La Hora mediante una acción de protección en la que alegó la vulneración de los derechos constitucionales a obtener información veraz y a la rectificación de la información del Estado ecuatoriano. El juez de primera instancia aceptó la acción, declaró la vulneración de derechos y dispuso, entre otras medidas, que el medio de comunicación publique una rectificación y disculpas públicas. Esta sentencia fue ratificada por los jueces de apelación, quienes agregaron que el Diario había vulnerado el derecho a la honra del Estado.

En su sentencia, la CC se pronunció sobre dos temas. Por una parte, si el Estado puede ser titular de derechos constitucionales y solicitar la tutela de estos derechos a través de la acción de protección. Por otra, desarrolló el alcance del derecho a la libertad de expresión y su relación con el derecho a la rectificación y respuesta.

Sobre el primer tema, la CC revirtió el criterio jurisprudencial vigente desde 2009, según el cual todas las personas, incluidas las entidades públicas, podían reclamar la vulneración de derechos mediante garantías jurisdiccionales. La CC señaló que los derechos son atributos inherentes a los seres humanos y, en el caso ecuatoriano, a la naturaleza. "Los derechos nacieron para proteger a los individuos de los excesos del poder público", son "límites al poder del Estado" y este último "está llamado a respetarlos y protegerlos" (CC, Sentencia No. 282-13-JP/19, 2019, párr. 29 y 30), acotó la Corte. En esta línea, la Corte afirmó que el Estado no es titular del derecho al honor, a la información veraz y a la rectificación, sino que estos derechos están derivados de la dignidad humana, y concluyó que lo declarado por los jueces inferiores era improcedente ${ }^{6}$.

6 La Corte reconoció que, en aras de garantizar el ejercicio de la defensa en condiciones igualdad dentro de procesos administrativos y judiciales, las personas jurídicas de derecho público pueden activar garantías jurisdiccionales que busquen tutelar el derecho a la tutela judicial efectiva, al debido proceso y a la seguridad jurídica en su dimensión procesal. 
Sobre el segundo tema, la Corte indicó que los medios de comunicación promueven el ejercicio de la libertad de expresión en su dimensión individual, consistente en la posibilidad de expresarse y utilizar los medios adecuados para difundir un mensaje al mayor número de destinatarios, y su dimensión social, que permite a las personas recibir información, opiniones y expresiones ajenas. Las autoridades públicas, por ello, deben abstenerse de limitar u obstaculizar el ejercicio de la libertad de expresión y la libertad de prensa, cuyo ejercicio está protegido por "una presunción de constitucionalidad” (CC, Sentencia No. 282-13-JP/19, 2019, párr.63).

La Corte agregó que el ejercicio de la libertad de expresión, en línea con los artículos 13 numeral 2, 18 y 30 de la CADH, puede generar responsabilidades ulteriores que "deben: (i) estar expresamente previstas en una ley, (ii) perseguir un fin legítimo y, (iii) ser idóneas, necesarias y estrictamente proporcionales" para asegurar "a. el respeto a los derechos o a la reputación de los demás, o b. la protección de la seguridad nacional, el orden público o la salud o la moral públicas" (UN-OHCHR, WGAD, 2019, párr. 111; CC, Sentencia No. 28213-JP/19, 2019, párr. 61).

La CC además destacó que, si bien existen limitaciones a la libertad de expresión, la aplicación de las mismas debe ser excepcional y añadió que ciertos discursos -en particular aquellos sobre el interés público, asuntos políticos, sobre personas que ocupan o pretenden ocupar cargos públicos y aquellos relacionados con expresiones que viabilizan el ejercicio efectivo de derechos constitucionales- tienen una protección constitucional especial, configurada a partir de una "presunción de constitucionalidad". Ello se debe a que este tipo de discursos:

(i) fomentan el debate y el cuestionamiento de las posturas y decisiones de los distintos órganos del Estado; (ii) promueve la participación ciudadana en ejercicio de las actividades, cumplimiento de competencias estatales y diseño de políticas públicas; (iii) permite a los ciudadanos formarse una opinión, adoptar posturas y participar de manera efectiva e informada del proceso democrático; (iv) facilita el escrutinio y vigilancia respecto de las actividades estatales. (CC, Sentencia No. 282-13JP/19, 2019, párr. 66) 
La legitimidad de las restricciones a la libertad de expresión, acotó la Corte, deben evaluarse en función de los estándares de reporte fiel, según el cual "no se podría trasladar la responsabilidad originada en los contenidos al medio que los reproduce citando su fuente" (CC, Sentencia No. 282-13-JP/19, 2019, párr. 81) y de real malicia, lo que implica que quien alega la restricción del derecho a la libertad de expresión debe comprobar que la difusión de información se ha realizado "con la intención de causar un daño y con conocimiento de la falsedad de la información difundida, o con un desprecio evidente por la veracidad de los hechos" (CC, Sentencia No. 282-13-JP/19, 2019, párr. 93).

Sobre la diferencia del derecho a la rectificación y el derecho a la réplica, la Corte expresó:

(...) En caso de que la información difundida sea falsa o errónea, corresponde solicitar una rectificación a fin de que se corrija tal situación. En los casos en que terceros requieran pronunciarse sobre la información difundida por considerase agraviados sobre la base de motivos distintos a la falsedad de la información, corresponde solicitar un espacio para ejercer el derecho a la réplica o respuesta. (CC, Sentencia No. 282-13JP/19, 2019, párr. 76)

En el caso concreto, la Corte consideró que la información publicada por el Diario La Hora aludía al gasto público, por lo que gozaba de protección especial, y adicionalmente cumplía con el estándar de veracidad establecido en el artículo 18 de la Constitución, en tanto dicho medio de comunicación reprodujo información manifestada por terceros, sin realizar apreciaciones subjetivas y citando la fuente.

Además de revertir las decisiones de los jueces inferiores y declarar que las mismas habían limitado inconstitucionalmente el derecho a la libertad de expresión del Diario La Hora, la CC ordenó la difusión de la sentencia con especial énfasis a los operadores de justicia encargados de resolver garantías jurisdiccionales. 


\subsection{Derechos de participación}

Además de los derechos tradicionalmente vinculados con la democracia representativa, como el derecho a elegir, ser elegido y conformar organizaciones políticas, el artículo 61 de la Constitución ecuatoriana establece otros derechos relacionados con la democracia directa y participativa, como la iniciativa popular normativa, la consulta popular, la revocatoria del mandato y la fiscalización de las autoridades públicas. De hecho, la Constitución denomina a estos derechos políticos como derechos de participación (Noguera \& Navas, 2016).

Los fallos más importantes en términos de estos derechos han sido emitidos en procesos en los que la CC se ha pronunciado sobre la procedencia de consultas populares y propuestas de reforma constitucional. Como explicamos anteriormente, en estos casos la Corte ejerce control constitucional previo y automático, dictaminando la constitucionalidad tanto de propuestas de a consultas populares, así como de iniciativas de reforma de la Carta Suprema. Estas propuestas pueden provenir de la ciudadanía, del Presidente de la República o de un grupo de legisladores.

En los casos 4-19-RC, 5-19-RC, 7-19-RC y 8-19-RC, la Corte resolvió varias iniciativas de reforma constitucional que pretendían regular el sufragio pasivo exigiendo que los candidatos a legisladores cuenten un título profesional de tercer nivel y experiencia profesional mínima de diez años. La CC estimó que esta propuesta buscaba introducir un "componente elitista" en la integración de la Asamblea Nacional. Este requisito, argumentó la Corte, podría restringir el derecho a ser elegido de más del $91 \%$ de la población total, incluido el 96\% de los afroecuatorianos, $97 \%$ de los montubios y $98 \%$ de los indígenas. La Corte además manifestó que "la sabiduría práctica que algunos ciudadanos indígenas alcanzan a partir de los conocimientos ancestrales de su respectiva comunidad (que, sin duda, los capacitaría para desempeñarse como senadores) es imposible de ser acreditada mediante un título universitario" (CC, Dictamen No. 4-19-RC/19, 2019, párr. 30.5). En definitiva, la CC dictaminó que estas propuestas de reforma constitucional limitaban derechos políticos y, por ello, no podían ser tramitadas a través del procedimiento de enmienda constitucional. 
También, sobre el sufragio pasivo, la Corte resolvió una propuesta orientada a instituir una prohibición constitucional para que aquellos ciudadanos llamados a juicios penales no puedan ser candidatos a asambleístas. La Corte consideró que esta iniciativa restringía la presunción de inocencia de las personas, misma que según la Constitución solo puede ser desvirtuada luego de una sentencia condenatoria ejecutoriada.

Quizás uno de los fallos más relevantes sobre el derecho a elegir y ser elegido fue el dictamen No. 7-19-RC/19, en el que la CC cambió el precedente sobre la eliminación de los límites constitucionales a la reelección, adoptada por los anteriores miembros del organismo (CC, Dictamen No. 7-19-RC/19, 2019).

En el dictamen No. 1-14-DRC-CC, de 2014, la Corte inicialmente había señalado que la reelección indefinida de las autoridades de elección popular, siempre y cuando se realicen elecciones periódicas, suponía una ampliación del sufragio activo y pasivo de las autoridades y los ciudadanos. Con esta polémica interpretación, la Corte habilitó la enmienda constitucional de las reglas de reelección, pasando de una fórmula de reelección limitada, que habilitaba la reelección por una sola vez de manera inmediata o no, a un sistema de reelección indefinida, que posibilita la reelección sin límites de las autoridades (CC, Dictamen No. 001-14-DRC-CC, 2014).

En 2019, la CC modificó esta interpretación e indicó que no existe un derecho a la reelección, que la eliminación de los límites a la reelección no amplía derechos de participación y que más bien estas limitaciones son regulaciones legítimas que coadyuvan a la alternancia democrática de las autoridades electas en sus cargos. La Corte además resaltó que la reelección indefinida podría distorsionar el sistema democrático, volviéndolo incompatible con un sistema de gobierno democrático, presidencial y republicano.

En otro tema, la Constitución establece un sistema de financiamiento mixto de las organizaciones políticas. En el caso 10-19-RC, la Corte conoció una propuesta de reforma que buscaba eliminar el financiamiento público de las mismas. La CC manifestó que las organizaciones 
políticas son "canales de expresión de parte de la ciudadanía en los temas de interés y quehacer público" (CC, Dictamen No. 10-19-RC/20, 2020, párr. 43) y rechazó la propuesta de reforma, bajo el argumento de que el financiamiento público -más precisamente, el fondo partidario permanente- es un mecanismo que protege la participación y la igualdad material de las distintas organizaciones políticas.

Otro giro jurisprudencial importante en materia de derechos políticos, relacionado con el ejercicio de la iniciativa ciudadana para convocar a una consulta popular, se produjo en el caso 1-19-CP. Con anterioridad, en el Dictamen No. 1-13-DCP-CC de 2014, la CC había establecido que, previo a obtener un dictamen constitucional sobre la procedencia de una consulta popular, la ciudadanía debía presentar "el requisito de legitimidad democrática", es decir, el número de firmas requerido para la convocatoria a consulta popular (CC, Dictamen No. 001-13-DCP-CC, 2013)․

En contra de la argumentación sostenida por la anterior conformación de la CC, en el dictamen 1-19-CP/19, la magistratura sostuvo que obligar a la ciudadanía a recolectar firmas, sin tener la certeza sobre la constitucionalidad de la propuesta de consulta popular:

provoca dos efectos lesivos con relación al derecho de participación, uno directo y otro indirecto: el primero ocasiona un obstáculo injustificado que altera y agrava el proceso de consulta popular de iniciativa ciudadana. Y, el otro efecto, como consecuencia del primero, podría conducir a un desincentivo sistemático que disuada a los ciudadanos de promover consultas populares, debido a una exigencia previa que dificulta innecesariamente su derecho de participación. (CC, Dictamen No. 1-19-CP/19, 2019, párr. 23)

7 De acuerdo con el artículo 104 de la Constitución: "La ciudadanía podrá solicitar la convocatoria a consulta popular sobre cualquier asunto. Cuando la consulta sea de carácter nacional, el petitorio contará con el respaldo de un número no inferior al cinco por ciento de personas inscritas en el registro electoral; cuando sea de carácter local el respaldo será de un número no inferior al diez por ciento del correspondiente registro electoral". 
La Corte consideró que resultaba inoficioso solicitar miles de firmas que carecerían de validez si es que el organismo no emite un dictamen favorable. En consecuencia, el organismo concluyó que en virtud de una interpretación más favorable para la "efectiva vigencia del derecho de participación" (CC, Dictamen No. 1-19-CP/19, 2019, párr. 25) a ser consultado, primero se debe realizar el control de constitucionalidad de la pregunta y, una vez obtenido este dictamen de constitucionalidad, los ciudadanos deben acreditar el porcentaje de respaldo popular determinado en la Constitución y la ley.

Esta apertura jurisprudencial a la participación popular se extendió también a la posibilidad de realizar consultas populares sobre actividades extractivas de recursos naturales en los dictámenes 2-19-CP/19, 9-19-CP/19 y 10-19-CP/19. En estos pronunciamientos la Corte aclaró que la consulta popular, a más de un derecho de participación y de un mecanismo de democracia participativa y directa, es también una garantía de otros derechos. En esta línea, el organismo expresó que "no existe, en principio, una disposición constitucional que prohíba clara y expresamente que la ciudadanía pueda plantear como asunto de consulta popular temas relacionados con la explotación de recursos naturales no renovables y específicamente con actividades de minería” (CC, Dictamen No. 9-19-CP/19, 2019, párr. 21). Al contrario, la Corte consideró que "no solo el sistema democrático sino el régimen de desarrollo que establece la Constitución incluye expresamente la participación de los ciudadanos y ciudadanas como un derecho en sí mismo y como una garantía de todos los demás derechos constitucionales" (CC, Dictamen No. 9-19-CP/19, 2019, párr. 21).

A partir de este cambio jurisprudencial se han propuesto varias iniciativas de consultas populares, referéndums e incluso convocatorias a asambleas constituyentes a lo largo de 2019. En todos estos casos la Corte examinó cuál es la vía idónea de reforma conforme a la Constitución.

Finalmente, vale destacar la protección constitucional del "derecho a la protesta pacífica" expresada por la Corte en el caso 5-19-EE. En el contexto de las manifestaciones de varios sectores sociales, especialmente de las organizaciones indígenas, en contra del gobierno 
de Lenín Moreno, la Corte controló la constitucionalidad de las medidas adoptadas por el Ejecutivo para aquietar las protestas ciudadanas. La Corte señaló que las medidas de suspensión provisional de las libertades de reunión y de libertad no debían afectar el derecho constitucional a la resistencia "del que son titulares todas y todos los ecuatorianos, siempre que el mismo sea ejercido de manera pacífica y sin atentar contra los derechos, libertades y garantías de terceros" (CC, Dictamen No. 5-19-EE/19A, 2019, párr. 20). Cabe resaltar que el artículo 98 de la Constitución ecuatoriana señala expresamente que los ciudadanos podrán ejercer "el derecho a la resistencia frente a acciones $\mathrm{u}$ omisiones del poder público o de las personas naturales y jurídicas no estatales que vulneren o puedan vulnerar sus derechos constitucionales" (CRE, 2008).

\subsection{Los derechos de participación y el cogobierno en las instituciones de educación superior}

En el caso 14-11-IN, la Corte resolvió una acción pública de inconstitucionalidad formulada, por la Federación Estudiantes Universitarios del Ecuador, en contra del artículo 47 y 60 de la Ley Orgánica de Educación Superior que preveía la reducción los porcentajes de participación estudiantil en organismos colegiados de cogobierno universitario, además de la reducción el peso relativo del voto de los estudiantes en la elección de los rectores y vicerrectores de estas casas de estudio. En la sentencia de mayoría, la Corte estimó que esta disminución era injustificada y regresiva para los derechos de participación de los estudiantes. En línea con el artículo 95 de la Constitución, esta decisión amplió el campo de acción de los derechos políticos no solamente en ámbitos tradicionales como las instituciones público-estatales, sino también en instituciones sociales de diversa índole como las universidades (CC, Sentencia No. 14-11-IN/20, 2020). 


\subsection{Derecho a la salud obstétrica de mujeres embarazadas y violencia obstétrica}

En el caso 904-12-JP la Corte abordó el derecho a la salud, con énfasis en la protección constitucional orientada a evitar y erradicar la "violencia obstétrica" en contra de las mujeres, además del derecho a la seguridad social. El caso trata sobre una mujer embarazada que presentó fuertes dolores de parto y acudió a un hospital público en el que se le negó atención médica por una presunta mora patronal en sus aportes a la seguridad social. Como consecuencia, la mujer dio a luz sin asistencia y sufrió un desgarro de cuello uterino.

La CC señaló que las mujeres embarazadas, de acuerdo con los artículos 35 y 43 de la Constitución, forman parte de un grupo de atención prioritaria. Ello obliga al Estado a brindarles a ellas y a los recién nacidos servicios especializados, oportunos, adecuados y personalizados de manera preferente sobre otras personas y grupos (CC, Sentencia No. 904-12-JP/19, 2019, párr. 34).

En el caso de las mujeres embarazadas, la Corte resaltó que, según el artículo 363 numeral 6 de la Constitución, el Estado es responsable de "asegurar acciones y servicios de salud sexual y reproductiva, y garantizar la salud integral y la vida de las mujeres, en especial durante el embarazo, parto y postparto", añadiendo que el incumplimiento de esta obligación "tiene graves consecuencias para los derechos de las mujeres embarazadas" (CC, Sentencia No. 904-12-JP/19, 2019, párr.30).

En relación con el derecho a la salud, la CC desarrolló su contenido sobre la base de cuatro elementos esenciales establecidos en la Observación General (OG) No. 14 del Comité de los Derechos Económicos, Sociales y Culturales de la Organización de las Naciones Unidas: la disponibilidad, la accesibilidad, la aceptabilidad y la calidad. En el caso concreto, sostuvo que la atención médica incumplió con estos elementos debido a que: 
el personal no actúo con la debida diligencia requerida porque pese a existir una emergencia dio prioridad a una supuesta mora patronal (...) volvió inaccesible [la atención médica] por una cuestión burocrática y un requisito innecesario, que no dependía de la persona afiliada y que, en la realidad ni siquiera fue incumplido. (CC, Sentencia No. 904-12JP/19, 2019, párr. 54)

Añadió que el hospital "no prestó la atención personalizada que la paciente necesitaba” (CC, Sentencia No. 904-12-JP/19, 2019, párr. 58) y dejó de "proporcionar cama, disponer el personal especializado para el parto y alumbramiento, poner a disposición de los equipos y el instrumental necesario y así evitar que la paciente dé a luz en un lugar y momento inadecuado" (CC, Sentencia No. 90412-JP/19, 2019, párr. 60).

También sobre la base de la OG No. 14, la Corte expresó que el derecho a la salud impone tres obligaciones generales: respetar, proteger y cumplir, que en el caso fueron inobservadas por el Estado principalmente porque el hospital demandado negó la atención requerida alegando un presunto incumplimiento de un requisito que, como observó la Corte, no se encontraba establecido en la ley (CC, Sentencia No. 904-12-JP/19, 2019, párr. 61).

Sobre la base de la Convención sobre la Eliminación de todas las Formas de Discriminación contra la Mujer (CEDAW) y la Convención de Belém do Pará, la Corte señaló que la violencia obstétrica implica la negación del derecho a la salud de la mujer embarazada y, por ello, constituye un trato discriminatorio. Además, con fundamento en el "Informe de la Relatora Especial sobre la violencia contra la mujer, enfoque basado en los derechos humanos del maltrato y la violencia contra la mujer en los servicios de salud reproductiva" (A/74/137), la Corte indicó que este tipo de violencia puede comprender entre otras: la despreocupación del cuerpo y procesos reproductivos de la mujer por parte del personal de salud, obligar a la mujer a dar a luz en condiciones inseguras, insalubres y sin el acompañamiento médico y no brindar atención oportuna y eficaz ante una emergencia obstétrica. 
La Corte concluyó que la accionante sufrió reiteradas prácticas de violencia obstétrica pues durante su embarazo no fue atendida por un ginecólogo, dio a luz sin la presencia de personal médico, su atención fue suspendida pese a tener una hemorragia uterina posparto, fue trasladada forzosamente a otro establecimiento sin tener en cuenta su grave estado de salud, fue separada de su hijo recién nacido y no tuvo información sobre su situación médica (CC, Sentencia No. 904-12-JP/19, 2019, párr. 69).

En relación con la seguridad social, la Corte expresó que este derecho, según los artículos 34, 367 y 369 de la Constitución y la Observación General No. 19 del Comité de DESC, incluye el acceso a la atención de salud y en particular la cobertura frente a la contingencia de maternidad. Estas prestaciones también implican tratamientos adecuados durante el período prenatal, el parto y el período posnatal (CC, Sentencia No. 904-12-JP/19, 2019, párr. 75).

La CC destacó que la cobertura de las prestaciones de seguridad social puede ser suspendida únicamente por causas razonables, proporcionadas y transparentes, que deben estar previstas en la legislación. En la legislación ecuatoriana, agregó la magistratura, no se permite suspender la atención de salud por mora patronal. Al exigir el pago de contribuciones, en consecuencia, la Corte consideró que se impuso un requisito arbitrario que impidió a la mujer embarazada el acceso a la cobertura y servicios de salud (CC, Sentencia No. 90412-JP/19, 2019, párr. 76 y 77).

Entre las medidas de reparación integral dispuestas por la Corte se puede mencionar: i. una compensación económica a la accionante por los gastos de salud en los que incurrió la accionante, más el monto de $\$ 5.000,00$, por daños inmateriales; ii. disculpas públicas por parte del Instituto Ecuatoriano de Seguridad Social (IESS); iii. que el IESS y el Ministerio de Salud Pública elaboren una guía integral de atención a mujeres embarazadas y prevención de violencia obstétrica; y iv. que estas instituciones elaboren una evaluación técnica de los centros de salud para verificar que los mismos cuenten con condiciones adecuadas para atender mujeres embarazadas. 


\subsection{El derecho a la salud de las personas privadas de libertad}

En el caso 209-15-JH y acumulado, la Corte Constitucional analizó la procedencia de un hábeas corpus propuesto por personas con enfermedades crónicas y privadas de su libertad. Al respecto, la CC estableció que estas personas presentan una condición de doble vulnerabilidad al estar privados de libertad y padecer enfermedades catastróficas, por lo que la ausencia de tratamiento médico ponía en riesgo su vida. (CC, Sentencia No. 209-15-JH/18 y acumulado, 2019, párr. 54).

Frente a esta situación, la CC señaló que limitar o impedir el acceso a tratamientos médicos a personas privadas de libertad, afecta al derecho a la salud y adicionalmente podría derivar en tratos crueles, inhumanos o degradantes. En este sentido, el Estado se convierte en un garante de que la privación de libertad no implique un menoscabo del derecho a la salud. Para tal efecto, las personas privadas de libertad deben acceder a servicios de salud a través de las siguientes vías: i. centros médicos dentro del lugar de privación de libertad; ii. atención dentro del sistema de salud pública cuando la persona requiera tratamiento especializado; y iii. excepcionalmente a través de medidas alternativas a la privación de libertad conforme a los límites establecidos en la ley.

Sobre este último punto, la CC enfatizó que estas medidas proceden únicamente si se cumplen dos condiciones. Por un lado, si el centro de privación de libertad no puede brindar tratamiento médico en sus instalaciones, y por otro, cuando tampoco sea posible acceder a estos tratamientos fuera del centro de privación de libertad en coordinación con el sistema de salud pública y el debido resguardo de la fuerza pública. Esta regla aplica también para las personas que se encuentren detenidas bajo prisión preventiva. Finalmente, la CC indicó que la persona que sufre de enfermedades catastróficas no tiene la obligación de "agotar los mecanismos legales o administrativos tendientes a recuperar su libertad o solicitar la atención de salud, previo a la interposición de un hábeas corpus" (CC, Sentencia No. 209-15JH/18 y acumulado, 2019, párr. 53). 


\subsection{Seguridad social}

Los casos 23-18-IN y 49-16-IN fueron conocidos por la CC a raíz de una acción pública de inconstitucionalidad presentada por colectivos de afiliados al Instituto Ecuatoriano de Seguridad Social (IESS). En ambos casos la Corte desarrolló el contenido del derecho a la seguridad social, en particular de las prestaciones a la decimotercera y decimocuarta pensiones jubilares y del auxilio de funerales.

Dentro de la causa 49-16-IN, se impugnó la constitucionalidad de una resolución del IESS que estableció que cuando un jubilado retorna a laborar bajo relación de dependencia se le descuenta temporalmente el $40 \%$ de su pensión. Este rubro proviene de un aporte que hace el Estado para financiar la seguridad social. El descuento se hace durante el tiempo dure el trabajo en relación de dependencia y únicamente si los nuevos ingresos del trabajador superan el valor de una canasta básica familiar ${ }^{8}$ (CC, Sentencia No. 49-16-IN/19, 2019, párr. 43). Cuando la persona regresa a la condición de jubilado, nuevamente percibe el mencionado subsidio (40\%) y además tiene derecho a una mejora en su pensión. Este aumento no puede superar a la pensión máxima vigente a la fecha de la concesión inicial del beneficio (CC, Sentencia No. 49-16-IN/19, 2019, párr. 70).

En este caso, la Corte analizó si el descuento significa una restricción desproporcionada e injustificada en los ingresos del jubilado. La magistratura argumentó que la calidad de vida e ingresos no se ven afectados ya que la persona percibe el $60 \%$ de su pensión más su remuneración (CC, Sentencia No. 49-16-IN/19, 2019, párr. 59). Además, señaló que el $40 \%$ descontado sirve para que el Estado -que tiene recursos escasos- financie la seguridad social de otros ciudadanos en atención a los principios de solidaridad, obligatoriedad, subsidiariedad y universalidad (CC, Sentencia No. 49-16-IN/19, 2019, párr.66).

Por otra parte, la CC también analizó la constitucional del límite de mejora en relación con la fecha de concesión inicial de la pensión. 
Al respecto, la CC determinó que este límite perjudicaría el cálculo de la reliquidación de la persona que regresa a la condición de jubilado y por lo tanto vulnera principio de desarrollo progresivo de la seguridad social. Bajo estas consideraciones, la CC declaró la constitucionalidad de la norma, siempre que se tenga como límite para la reliquidación la pensión máxima a la fecha del nuevo cese del trabajador (CC, Sentencia No. 49-16-IN/19, 2019, párr. 74).

En el segundo caso (23-18-IN), se realizó el análisis constitucional sobre una resolución del IESS que efectuó un descuento del 2,76\% sobre las pensiones de los jubilados con el objeto de financiar parcialmente la decimotercera y decimocuarta pensiones jubilares y del auxilio de funerales ${ }^{9}$. La CC manifestó que de acuerdo con el artículo 369 de la Carta Fundamental, las prestaciones de la seguridad social deben crearse únicamente cuando estén debidamente financiadas (CC, Sentencia No. 23-18-IN/19, 2019, párr. 44). Adicionalmente, que según el artículo 371 de la Constitución el financiamiento de las prestaciones no puede ser deducido -incluso parcialmente- de las pensiones de los jubilados y que su financiamiento debió darse, de manera suficiente, mientras fueron afiliados activos (CC, Sentencia No. 23-18-IN/19, 2019, párr. 45).

De lo anterior, se deriva que el ejercicio de derechos cuya satisfacción se concreta en la percepción de un beneficio económico -como una pensión jubilar-, no puede ser disminuido a menos que exista una razón plenamente justificada como lo prescribe el artículo 11.8 de la Constitución. Por estas razones, la CC resolvió que el referido descuento del $2,76 \%$ constituye una retención inconstitucional de la pensión por jubilación y que los efectos de la sentencia no son retroactivos (CC, Sentencia No. 23-18-IN/19, 2019).

Finalmente, la CC hizo un llamado de atención a la Función Legislativa, para que futuras leyes que plantean beneficios de seguridad social tengan un tratamiento técnico y cuenten con el debido

9 La $13^{\circ}$ pensión equivale a una pensión adicional, la $14^{\circ}$ pensión equivale a un salario básico (USD 400), y el auxilio de funerales consiste en el pago de servicios exequiales. 
financiamiento a fin de no poner en peligro la sostenibilidad de la seguridad social (CC, Sentencia No. 23-18-IN/19, 2019, párr.48).

\subsection{Derechos de las comunidades, pueblos y nacionalidades}

Pese a que la Constitución ecuatoriana incluye un profuso catálogo de derechos colectivos, entre los que destacan los derechos de las comunidades, pueblos y nacionalidades, el desarrollo de estos en la jurisprudencia constitucional durante la gestión de la removida CC fue más bien incipiente. El retroceso de la justicia indígena y su problemática relación con la justicia ordinaria reflejan particularmente las limitaciones que la CC legitimó hasta el año 2018 (Santos y Grijalva, 2012).

Vale anotar que el artículo 57 numeral 10 de la Constitución (2008) consagra el derecho de las comunidades pueblos y nacionalidades a "crear, desarrollar, aplicar y practicar su derecho propio o consuetudinario, que no podrá vulnerar derechos constitucionales (...)”. La justicia indígena, en el marco del Estado plurinacional e intercultural, no solo es un derecho, sino que también forma parte de la organización institucional de la Función Judicial. De hecho, el artículo 171 de la Carta Suprema (2008) señala que "el Estado garantizará que las decisiones de la jurisdicción indígena sean respetadas por las instituciones y autoridades públicas. Dichas decisiones estarán sujetas al control de constitucionalidad".

Durante el último año, la CC se pronunció sobre los derechos de las comunidades, pueblos y nacionalidades a mantener sus sistemas jurídicos propios en dos casos. Ambos llegaron a conocimiento de la Corte mediante peticiones formuladas por la ciudadanía para reformar la Constitución. En el caso 5-19-RC, un grupo de ciudadanos propuso reformar la Constitución para crear un sistema estatal único de justicia indígena que opere de manera paralela al de la justicia ordinaria. Como se expuso previamente, la CC es competente para declarar, a partir de un control constitucional previo, si las propuestas de reforma constitucional proceden mediante los mecanismos propuestos por los peticionarios 
Respecto a esta propuesta de reforma, la CC resaltó que el Ecuador es un Estado intercultural y plurinacional, que reconoce, protege y garantiza la coexistencia y el desarrollo de sistemas normativos de las comunidades, pueblos y nacionalidades indígenas. La Corte señaló que estas comunidades tienen, según el artículo 57 numeral 10, "el derecho a [conservar y desarrollar] su propio Derecho", derivado del derecho a la autodeterminación colectiva. Este derecho a su propio Derecho incluye las facultades para designar a sus autoridades, generar sus propias normas y decisiones y ejercer facultades jurisdiccionales.

La Corte además interpretó que, si bien la Constitución ecuatoriana reconoce a la justicia indígena, en singular, en realidad la misma alude y protege a sistemas heterogéneos que incluyen diversos procedimientos y normas que conforman el conjunto de manifestaciones de justicia propias de las comunas, comunidades, pueblos y nacionalidades indígenas. La Corte resaltó:

Los derechos colectivos de los pueblos y nacionalidades indígenas crean una esfera de autonomía que excluye la intromisión del Estado en el desarrollo, mantenimiento y aplicación de sus instituciones y sistemas jurídicos propios. La única justificación legítima para la intromisión del Estado en esta esfera es la protección de los derechos constitucionales. (CC, Dictamen Nº. 5-19-RC/19, 2019, párr. 32)

Al igual que en el caso 5-19-RC, en el caso 9-19-RC, la Corte sostuvo que la creación de un sistema institucional único de justicia indígena "no fortalecería la justicia indígena, sino que las privaría de su autonomía al ser absorbidas por instituciones ajenas a su Derecho e instituciones propias" (CC, Dictamen No. 9-19-RC/19, 2019, párr. 18). Además, reiteró que la Constitución protege el derecho de cada comunidad, pueblo y nacionalidad a desarrollar sus propias costumbres y prácticas. En suma, la Corte dictaminó que la reforma propuesta restringía el derecho a la autodeterminación de las comunidades, pueblos y nacionalidades. 


\subsection{Libertad ambulatoria y hábeas corpus}

De acuerdo con la Constitución ecuatoriana, el hábeas corpus es una garantía jurisdiccional que protege el derecho a la libertad ambulatoria frente a detenciones ilegales, arbitrarias o ilegítimas, además de otros derechos como la vida y la integridad física, incluso de personas en condición de movilidad. Los casos analizados llegaron a la CC a través del mecanismo de selección y revisión mencionado previamente. En la sentencia 159-11-JH, la CC examinó el caso de una persona extranjera detenida de forma ilegítima dado que la única justificación para la detención fue ser de una nacionalidad distinta. Frente a esta situación, el extranjero presentó una acción de hábeas corpus que fue negada en dos instancias. Al respecto, la Corte estimó que la garantía no fue eficaz, dado que los jueces inferiores argumentaron que existía una orden de deportación y que la prueba presentada por el accionante fue insuficiente, mas no valoraron que la detención se produjo sin delito flagrante, tampoco existió una boleta de prisión emitida por autoridad competente y se atentó contra la dignidad de la persona durante la privación de libertad que duró más de cuarenta días (CC, Sentencia No. 159-11-JH/19, 2019). Adicionalmente, la CC señaló que un extranjero no puede ser privado de libertad por su condición migratoria y que los establecimientos para este efecto están prohibidos. Por estas razones el organismo declaró vulnerados los derechos de libertad, igualdad, debido proceso, integridad y a migrar. Frente a estas violaciones la CC dictó medidas de reparación integral que incluyeron: i. revocatoria de la decisión de los jueces inferiores y aceptación del habeas corpus, ii. que el Estado otorgue facilidades para el trámite de nacionalización por naturalización, iii. la difusión de la sentencia y iv. una compensación económica de USD 634,40, entre otras (ibídem).

Dentro de la causa 166-12-JH la CC revisó el caso de una persona detenida en contra de su voluntad en un "centro privado de desintoxicación”. La Corte estableció que la finalidad de la acción de hábeas corpus en estos casos consiste en: i. verificar el cumplimiento de las exigencias legales para la privación de libertad y ii. la recuperación de la libertad ambulatoria o la dignificación de las condiciones de privación de esta. Junto a esto, la Corte estimó que la manifes- 
tación de la voluntad libre e informada del titular del derecho -en los casos en que sea posible- es un elemento decisivo para determinar si la privación de libertad es arbitraria e ilegítima. Sobre la audiencia en la que se decide sobre el hábeas corpus, la CC resaltó que en estas diligencias se debe ordenar la comparecencia de la persona privada de libertad y que si existe duda sobre las versiones respecto de la privación se debe resolver a favor de la libertad.

\section{Otros casos relevantes de control de constitucionalidad}

\subsection{Inconstitucionalidad preventiva de la creación de un registro de violadores, abusadores y agresores sexuales}

En ejercicio del control de constitucionalidad preventivo, le corresponde a la CC pronunciarse sobre la procedencia de las objeciones por inconstitucionalidad formuladas por el Presidente a los proyectos de ley aprobados por la Asamblea Nacional. En el caso 5-19-OP, la Corte analizó la objeción presidencial del proyecto de Ley Orgánica de Registro Ecuatoriano de Violadores, Abusadores y Agresores Sexuales de Niñas, Niños y Adolescentes (Ley REVAAS). Este proyecto planteó la creación de un registro público de violadores, abusadores y agresores sexuales de menores de edad y su consecuente inhabilitación para el ejercicio de profesiones u oficios que involucren relaciones directas con niños, niñas y adolescentes, misma que duraría "por el mismo tiempo establecido en la sentencia condenatoria" (CC, Dictamen No. 5-19-OP/19, pág. 8).

La Corte argumentó que la creación de este registro: i. desconoce que, de acuerdo con los artículos 201, 202 y 203 de la Constitución, la rehabilitación es una de las finalidades de la pena; ii. discrimina a las personas debido a su pasado judicial; y iii. no cumple con el test de proporcionalidad. Sobre esto último, la CC señaló que la creación del registro público no era idónea, en tanto "la eficacia de estas medidas para evitar la reincidencia de este tipo de delitos, han sido 
criticadas, pues no existe un consenso sobre real efecto que estas pueden generar en la sociedad y en las personas que se verían involucradas" (CC, Dictamen No. 5-19-OP/19, párr. 77), no era necesaria porque "existen medidas alternativas, tales como: la creación de protocolos de prevención, el fortalecimiento de la política pública de rehabilitación social, la implementación de políticas educativas" (CC, Dictamen No. 5-19-OP/19, párr. 79) y tampoco proporcional, por cuanto limita derechos laborales e impone una doble condena, sin que ello implique la consecución del derecho a la integridad personal de los niños, niñas y adolescentes. En síntesis, la Corte declaró la inconstitucionalidad por el fondo del proyecto de Ley REVAAS.

\subsection{Juzgamiento especializado de adolescentes infractores}

En el caso 9-17-CN, la CC fue consultada por jueces inferiores sobre la constitucionalidad de que un mismo juez trate las tres diferentes etapas del juzgamiento a adolescentes infractores: i. instrucción, ii. evaluación y preparatoria de juicio y iii. juicio (artículos 354, 356.7 y 357 del Código de la Niñez y Adolescencia, en adelante CNA). La CC razonó que no se cumple la garantía de ser juzgado por un juez imparcial si es un mismo juzgador quien sustancia la fase preparatoria y el juicio. En efecto, durante las dos primeras etapas del proceso de adolescentes infractores, el juzgador podría adquirir preconcepciones o sesgos por lo que a criterio de la CC se vuelve necesario que un juez distinto sustancie la fase de juicio. Por tales razones, la CC declaró la constitucionalidad condicionada del artículo 357 del CNA siempre que se interprete que el juez que conoce la primera y segunda fase debe ser distinto al juez que tramita la tercera fase del juicio a un adolescente infractor.

Por otra parte, la Corte señaló que para cumplir con el estándar previsto en el párrafo anterior deben existir como mínimo dos jueces por cada cantón y al menos uno de ellos debe ser especializado en adolescentes infractores. Sobre el alcance de la especialización, la CC estableció estos parámetros: 
i. conocimiento sobre derechos de niños, niñas y adolescentes (doctrina de protección integral), ii. compresión de la distinción entre la justicia de adolescentes infractores y otras formas de hacer justicia, en particular la justicia penal de adultos, iii. compromiso con los fines del proceso de adolescentes infractores. (CC, Sentencia No. 09-17-CN/19, 2019, párr. 42)

Finalmente, la Corte dispuso al Consejo de la Judicatura ${ }^{10}$, entre otras medidas, que dentro de un plazo razonable diseñe y ejecute un plan para la "Administración de justicia para adolescentes infractores, que incluya tanto el modelo de justicia especializada como la formación continua y la acreditación a operadores de justicia especializada" (CC, Sentencia No. 09-17-CN/19, 2019, párr.78.4).

\subsection{Momentos de control de la reforma constitucional}

Dentro del dictamen 4-18-RC/19, la CC conoció tres propuestas de modificación constitucional y definió el alcance de la intervención del organismo en cuanto al control de constitucionalidad de este tipo de peticiones. La Corte determinó que el control de la reforma constitucional puede ser ex ante cuando se dictamina sobre la vía adecuada para modificar la Constitución y cuando se resuelve sobre la constitucionalidad de la convocatoria a referéndum constitucional aprobatorio. El control también puede ser ex post si la Corte analiza la constitucionalidad de las modificaciones ya aprobadas.

\subsection{El control constitucional de los tratados internacionales}

La Constitución ecuatoriana establece el control constitucional de los tratados internacionales celebrados por el Estado ecuatoriano. Este control puede ser ex ante y ex post, es decir, antes y después de la ratificación del Tratado. En el control ex ante, la Corte debe dictaminar si los tratados suscritos por el Ejecutivo requieren de

10 El Consejo de la Judicatura es el órgano de administración y disciplina de la Función Judicial. 
aprobación legislativa, entre otros supuestos, porque comprometen la política económica del Estado o vinculan al país en acuerdos de integración y de comercio. Si se dictamina que el tratado requiere de aprobación legislativa, la Corte debe pronunciarse sobre la constitucionalidad de este.

En el caso 2-19-TI, la Corte estudió la constitucionalidad del Acuerdo de Asociación Económica Inclusiva suscrito entre el Ecuador y los Estados de la Asociación Europea de Libre Comercio (AELC). Este Acuerdo establece un área de libre comercio entre los Estados parte y regula, entre otros aspectos, el comercio de mercaderías y servicios, asuntos de propiedad intelectual, derecho de la competencia, cooperación, solución de controversias y contratación pública. Sobre este último aspecto, el dictamen de la Corte advirtió que el Acuerdo con la AELC incluía una cláusula de trato nacional para proveedores extranjeros, prohibiendo expresamente tratar a un proveedor extranjera de manera menos favorable que a un proveedor extranjero.

La Corte señaló que, si bien las disposiciones del Acuerdo relativas a la contratación pública mantienen conformidad con los artículos 284, 304, 337 y 416 de la Constitución, "en la medida en la que aspiran a impulsar la inserción estratégica del país en la economía mundial, asegurar la participación de la economía ecuatoriana en el contexto regional y mundial, y fomentar el comercio e inversión entre los Estados" (CC, Dictamen No. 2-19-TI/19, 2019, párr. 95), la cláusula de trato nacional en materia de contratación pública contraviene lo establecido en el artículo 288 de la Constitución, que dispone: "las compras públicas cumplirán con criterios de eficiencia, transparencia, calidad, responsabilidad ambiental y social. Se priorizarán los productos y servicios nacionales". Por ello, la Corte dictaminó la constitucionalidad del Acuerdo, "siempre y cuando se establezca una reserva con respecto al Artículo 6.4 del Capítulo 6" (CC, Dictamen No. 2-19-TI/19, 2019, párr. 154.a), relativa a la cláusula de trato nacional a proveedores extranjeros. 


\subsection{Principio de legalidad y reserva de ley en materia tributaria}

En el caso 27-12-IN, la Corte examinó una demanda de inconstitucionalidad planteada en contra de los numerales 4 y 5 del artículo 55 de la Ley de Régimen Tributario Interno, que disponen gravar con tarifa cero el impuesto al valor agregado (IVA) de ciertos productos del sector agropecuario definidos en la propia Ley e importados o adquiridos en el mercado interno de acuerdo con listas que establecidas el Presidente de la República mediante decreto ejecutivo. En particular, los accionantes alegaron que las normas impugnadas vulneraban los principios de reserva de ley y de legalidad tributaria, pues la Constitución, en su artículo 301, establece que "sólo por iniciativa de la Función Ejecutiva y mediante ley sancionada por la Asamblea Nacional se podrá establecer, modificar, exonerar o extinguir impuestos" (CRE, 2008).

La sentencia de la CC indicó que el principio de legalidad en materia tributaria establece que "la creación, modificación o supresión de tributos debe ser efectuada a través de una ley, cuya expedición le corresponde a la Asamblea Nacional" (CC, Sentencia No. 27-12-IN/20, párr. 36), en tanto que el principio de reserva de ley "determina que todos los elementos de un tributo deberán estar previstos en la ley" (CC, Sentencia No. 27-12-IN/20, párr. 37). De acuerdo con estos principios, "la ley es la única forma idónea para contemplar la creación, modificación o supresión de un tributo" (CC, Sentencia No. 27-12IN/20, párr. 38) y "debe contener los elementos esenciales del mismo". Estos elementos esenciales son "el objeto imponible, los sujetos activo y pasivo, la cuantía del tributo o la forma de establecerla, las exenciones y deducciones" (CC, Sentencia No. 27-12-IN/20, párr. 38).

La Corte indicó que las disposiciones acusadas de inconstitucionales enlistan una serie de bienes cuya transferencia e importación grava IVA con tarifa cero. Estas disposiciones, agregó el organismo, no habilitan que los elementos esenciales del tributo consten en actos normativos distintos a una ley, sino que permiten que a través de un decreto ejecutivo se establezcan "elementos adicionales" de carácter formal que no alteran la naturaleza del tributo. Por ello, concluyó que 
las disposiciones impugnadas no inobservan los principios constitucionales de reserva de ley ni de legalidad en materia tributaria.

\subsection{Inconstitucionalidad de informe de Contraloría General del Estado}

Dentro del caso acumulado 5-13-IN la Corte analizó la constitucionalidad del inciso final del artículo 581 del Código Orgánico Integral Penal ecuatoriano. La Constitución ecuatoriana, en su artículo 233, establece que las acciones y las penas por delitos de peculado, cohecho, concusión y enriquecimiento ilícito son imprescriptibles. La disposición acusada como inconstitucional, sin embargo, requería que la Contraloría General del Estado (CGE) ${ }^{11}$ emitiese un informe administrativo previo a que la Fiscalía General del Estado ${ }^{12}$ pudiese ejercer la acción penal por delitos de peculado o enriquecimiento ilícito. En la práctica ello implicaba que estos delitos podían ser perseguidos únicamente durante siete años, pues este era el plazo para la emisión de informes con indicios de responsabilidad penal por parte de la CGE. Además, una vez iniciada la acción penal, se establecía el plazo de 180 días para su tramitación.

La CC argumentó que la Constitución asume "un especial compromiso para combatir la corrupción y la impunidad, como se desprende claramente de sus artículos 3(8), 83 (8), 204, 208 (1) y (4) y por ello los delitos de peculado, cohecho, concusión y enriquecimiento ilícito han sido declarados imprescriptibles (...) Ante esto, las regulaciones específicas de la Contraloría no pueden ser un óbice para que la Fiscalía pueda, en cualquier tiempo, iniciar, investigar y ejercer la acción penal en estos casos" (CC, Sentencia No. 05-13-IN/19, 2019, párr. 51). También señaló que "la subordinación del ejercicio de la acción penal pública al juzgamiento administrativo previo además de restringir las facultades propias de la Fiscalía, ocasiona que los

11 La CGE es un organismo especializado de control de las cuentas públicas.

12 La Fiscalía es el órgano encargado de la investigación pre procesal, procesal penal y del ejercicio de la acción penal pública. 
delitos de peculado y enriquecimiento ilícito tengan un obstáculo legal para ser perseguidos" (CC, Sentencia No. 05-13-IN/19, 2019, párr. 50). Por ello, la Corte acotó que "los términos administrativos para que la Contraloría pueda emitir informes de auditorías (siete años y 180 días) burlan el mandato constitucional de que estos delitos sean imprescriptibles" (ídem) y declaró la inconstitucionalidad del artículo 581 del COIP. Finalmente, el fallo reguló sus efectos en el tiempo a fin de evitar inseguridad jurídica e impunidad de delitos.

\section{Conclusiones}

Durante el último año, la Corte ha emitido varios fallos con impacto estructural para los derechos y las garantías constitucionales. Los retos de la CC son aún importantes. Entre otros asuntos, el organismo deberá definir la fina línea entre la autocontención judicial y la necesaria firmeza frente al control constitucional de los poderes públicos, desarrollar criterios específicos que permitan un ejercicio canalizado bajo los parámetros constitucionales de ciertos derechos, como la consulta popular o los derechos colectivos en el marco del Estado plurinacional; determinar el alcance tutelar de ciertas garantías jurisdiccionales, especialmente de la acción de protección y armonizar sus métodos interpretativos. Todo ello, mientras lidia con un grave problema de congestionamiento de causas judiciales, que aun obstaculizan las respuestas oportunas que debe emitir una CC aún en proceso de institucionalización y afianzamiento de su independencia. 


\section{Referencias Bibliográficas}

\section{Textos Jurídicos}

Andrade, K. (2013). La acción de protección desde la jurisprudencia constitucional. En Benavides, J. y Escudero, J. (eds.), Manual de Justicia Constitucional (pp. 111-136). Quito, Ecuador: Corte Constitucional del Ecuador.

Bazán, V. (2014). Control de las Omisiones Inconstitucionales e Inconvencionales: Recorrido por el derecho y la jurisprudencia americanos y europeos. Bogotá, Colombia: Fundación Konrad Adenauer, Programa Estado de Derecho para Latinoamérica.

Castro, JL., Llanos L., Valdivieso P., y García. W. (2016). La Acción de Protección como mecanismo de garantía de los derechos: Configuración institucional, práctica y resultados. Ius Humani, Revista de Derecho, 5, 9-44.

Castro, JL y van Dijck, G. (2017). Judicial Politics in Unconsolidated Democracies: An Empirical Analysis of the Ecuadorian Constitutional Court (2008-2016). Justice System Journal, 0 (0), 1-19.

González, J. (2017). From abusive constitutionalism to a multilayered understanding of constitutionalism: Lessons from Latin America. International Journal of Constitutional Law, 15 (2), 447-468. DOI: https://doi. org/10.1093/icon/mox017

Grijalva, A. (2012a). Constitucionalismo en Ecuador. Quito Ecuador: Centro de Estudios y Difusión del Derecho Constitucional.

Grijalva, A. (2012b). Independencia judicial y derechos en Ecuador. Ecuador Debate, 83, 35-42.

Jaramillo, JM. (2013). Las altas Cortes y la consolidación democrática en Ecuador luego de las reformas de 1998, 2008 y 2011. Colombia Internacional, 79, 121-154. DOI: https://doi.org/10.7440/colombiaint79.2013.05 
Landau, D. (2013). Abusive Constitutionalism. UC Davis Law Review, 47 (189), 189-259. Recuperado de https://lawreview.law.ucdavis.edu/issues/47/1/articles/47-1_Landau.pdf

Masapanta, C. (2013). Las medidas cautelares en la realidad constitucional ecuatoriana: eficacia en su aplicación y efectividad de la garantía. En Benavides, J. y Escudero, J. (eds.), Manual de Justicia Constitucional (pp. 245-271). Quito, Ecuador: Corte Constitucional del Ecuador.

Noguera Fernández, A., \& Navas, M. (2016). Los nuevos derechos de participación: ¿derechos constituyentes o constitucionales?: estudio del modelo constitucional de Ecuador. Madrid, España: Tirant lo Blanch.

Oyarte, R. (2016). Debido proceso. Quito, Ecuador: Corporación de Estudios y Publicaciones.

Oyarte, R. (2017). Acción extraordinaria de protección. Quito, Ecuador: Corporación de Estudios y Publicaciones.

Romero, D. (05 de febrero de 2020). La Corte Constitucional resolvió 595 causas en su primer año. Diario El Comercio. Recuperado de https://www.elcomercio.com/actualidad/corte-constitucional-resolucion-causas-ecuador.html

Romero, J. (2017). La cuestión de inconstitucionalidad en el Ecuador (Tesis de Maestría Universidad Andina Simón Bolívar). Recuperado de http://repositorio.uasb.edu.ec/bitstream/10644/5560/1/T2246-MDE-RomeroLa\%20cuestion.pdf

Salgado, H. (2013). ¿Guardianes o sepultureros de la Constitución 2008? Primer balance de la "Corte Constitucional en transición". Anuario Iberoamericano de Justicia Constitucional, (17), 311-324.

Santos, B. de S. y Grijalva, A. (2012). Justicia indígena, plurinacionalidad e interculturalidad en Ecuador. Quito, Ecuador: Editorial Abya-Yala.

Suárez, E. (2015). Distorsiones del sistema de selección y revisión de sentencias de la Corte Constitucional Ecuatoriana (Tesis de Maestría, 
Universidad Andina Simón Bolívar). Recuperado de http://repositorio. uasb.edu.ec/handle/10644/4769

Trujillo, P. (2019). Consultas y Referéndum Populares ¿¿Búsqueda de legitimidad política en Ecuador?. Apuntes Electorales: Revista del instituto electoral del Estado de México, 18 (60), 95-119.

Valle, A. (2010). Inconstitucionalidad por omisión en la jurisprudencia de la Corte Constitucional ecuatoriana. Sentencia No. 001-1L-SIO-CC (caso No. 0005-10-IO). Foro, Revista de Derecho, 13, 147-160.

\section{Jurisprudencia Constitucional}

Corte Constitucional del Ecuador. Dictamen No. 001-13-DCP-CC, Caso No. 002-10-CP de 25 de septiembre de 2013. Jueza sustanciadora: Wendy Molina Andrade.

Corte Constitucional del Ecuador. Sentencia No. 1-13-DCP, Caso No. 1-13CP de 15 de octubre de 2014. Juez ponente: Tatiana Ordeñana Silva.

Corte Constitucional del Ecuador. Dictamen No. 001-14-DRC-CC, Caso No. 001-14-RC de 31 de octubre de 2014. Jueza sustanciadora: Wendy Molina Andrade.

Corte Constitucional del Ecuador. Sentencia No. 1-14-DRC-CC, Caso No. 1-14-RC de 31 de octubre de 2014. Juez ponente: Wendy Molina Andrade.

Corte Constitucional del Ecuador. Sentencia No. 184-18-SEP-CC, Caso No. 1692-12-EP de 29 de mayo de 2018. Jueza sustanciadora: Marien Segura Reascos.

Corte Constitucional del Ecuador. Sentencia No. 1-19-CP/19, Caso No. 1-19CP de 16 de abril de 2019. Juez ponente: Carmen Corral Ponce.

Corte Constitucional del Ecuador. Sentencia No. 2-19-TI/19 Caso No. 2-19TI. de 30 de abril de 2019. Juez ponente: Daniela Salazar. 
Corte Constitucional del Ecuador. Sentencia No. 10-18-CN/19, Caso No. 1018-CN/19 de 12 de junio de 2019. Juez ponente: Alí Lozada Prado

Corte Constitucional del Ecuador. Sentencia No. 11-18-CN/19, Caso No. 1118-CN/19 de 12 de junio de 2019. Juez ponente: Ramiro Ávila.

Corte Constitucional del Ecuador. Sentencia No. 2-19-CP/19, Caso No. 2-19CP de 20 de junio de 2019. Juez ponente: Agustín Grijalva Jiménez.

Corte Constitucional del Ecuador. Sentencia No. 05-13-IN/19, Caso No. 0513-IN de 02 de julio de 2019. Juez ponente: Ramiro Ávila.

Corte Constitucional del Ecuador. Sentencia No. 9-17-CN/19, Caso No. 9-17-CN de 09 de julio de 2019. Juez ponente: Ramiro Ávila.

Corte Constitucional del Ecuador. Sentencia No. 4-18-RC/19, Caso No. 4-18RC de 09 de julio de 2019. Juez ponente: Carmen Corral Ponce.

Corte Constitucional del Ecuador. Sentencia No. 4-19-RC/19, Caso No. 4-19RC de 21 de agosto de 2019. Juez ponente: Alí Lozada Prado.

Corte Constitucional del Ecuador. Sentencia No. 282-13-JP/19, Caso No. 28213-JP de 04 de septiembre de 2019. Jueza ponente: Daniela Salazar Marín.

Corte Constitucional del Ecuador. Sentencia No. 5-19-RC/19, Caso No. 5-19RC de 04 de septiembre de 2019. Juez ponente: Daniela Salazar.

Corte Constitucional del Ecuador. Dictamen No. 9-19-CP/19, Caso No. 9-19CP de 17 de septiembre de 2019. Juez ponente: Agustín Grijalva Jiménez.

Corte Constitucional del Ecuador. Sentencia No. 10-19-CP/19, Caso No. 10-19CP de 17 de septiembre de 2019. Juez ponente: Karla Andrade Quevedo.

Corte Constitucional del Ecuador. Dictamen No. 5-19-EE/19A, Caso No. 5-19EE de 10 de octubre de 2019. Juez ponente: Enrique Herrería Bonnet.

Corte Constitucional del Ecuador. Sentencia No. 8-19-RC/19, Caso No. 8-19RC de 16 de octubre de 2019. Juez ponente: Hernán Salgado Pesantes. 
Corte Constitucional del Ecuador. Sentencia No. 7-11-IA/19, Caso No. 7-11IA de 28 de octubre de 2019. Juez ponente: Enrique Herrería Bonnet.

Corte Constitucional del Ecuador. Sentencia No. 603-12-JP/19 (acumulados), Caso No. 603-12-JP y 141-13-JP (acumulados) de 05 de noviembre de 2019. Juez ponente: Ramiro Ávila.

Corte Constitucional del Ecuador. Sentencia No. 49-16-IN/19, Caso No 4916-IN de 07 de noviembre de 2019. Jueza ponente: Carmen Corral Ponce.

Corte Constitucional del Ecuador. Dictamen No. 7-19-RC/19, Caso No. 7-19RC de 05 de noviembre de 2019. Jueza ponente: Carmen Corral Ponce.

Corte Constitucional del Ecuador. Sentencia No. 2019-15-JH/19 y (acumulado), Caso No. 209-15-JH y 359-18-JH (acumulado) de 12 de noviembre de 2019. Jueza ponente: Daniela Salazar Marín.

Corte Constitucional del Ecuador. Sentencia No. 9-19-RC/19, Caso No. 9-19RC de 12 de noviembre de 2019. Juez ponente: Ramiro Ávila.

Corte Constitucional del Ecuador. Sentencia No. 159-11-JH/19, Caso No. 159-11-JH. de 26 de noviembre de 2019. Juez ponente: Ramiro Ávila.

Corte Constitucional del Ecuador. Sentencia No. 5-19-OP/19, Caso No. 5-19OP de 05 de diciembre de 2019. Juez ponente: Enrique Herrería.

Corte Constitucional del Ecuador. Sentencia No. 904-12-JP/19, Caso No. 904-12-JP de 13 de diciembre de 2019. Juez ponente Ramiro Ávila.

Corte Constitucional del Ecuador. Sentencia No. 23-18-IN/19, Caso No. 2318-IN de 18 de diciembre de 2019. Juez ponente: Carmen Corral Ponce.

Corte Constitucional del Ecuador. Sentencia No. 166-12-JH/20, Caso No. 166-12-JH de 08 de enero de 2020. Juez ponente: Ramiro Ávila.

Corte Constitucional del Ecuador. Sentencia No. 525-14-EP/20, Caso No. 525-14-EP de 8 de enero de 2020. Jueza ponente: Daniela Salazar Marín. 
Corte Constitucional del Ecuador. Sentencia No. 27-12-IN/20, Caso No. 2712-IN de 20 de enero de 2020. Juez ponente: Hernán Salgado Pesantes.

Corte Constitucional del Ecuador. Sentencia No. 14-11-IN/20, Caso No. 1411-IN de 22 de enero de 2020. Juez ponente: Ramiro Ávila Santamaría.

Corte Constitucional del Ecuador. Sentencia No. 10-19-RC/20A, Caso No. 1019-RC de 11 de marzo de 2020. Juez ponente: Hernán Salgado Pesantes. 